\title{
LA INSERCIÓN LABORAL DE LA MUJER INMIGRANTE EN LOS SERVICIOS DE PROXIMIDAD EN CATALUÑA ${ }^{1}$
}

\author{
SÒNIA PARELLA I RUBIO
}

Universidad Autónoma de Barcelona

PALABRAS CLAVE ADICIONALES

Género, Inmigración, Mercado de Trabajo, Etnización

\author{
ADDITIONAL KEYWORDS \\ Gender, Inmigration, Labour Market, \\ Ethnisation
}

RESUMEN. La progresiva concentración de mujeres inmigrantes en los servicios de proximidad revela un proceso de triple discriminación laboral en la sociedad receptora, -clase social, género y etnia. El artículo analiza, por un lado, la posición de la mujer inmigrante en el mercado laboral catalán, lo que permite evidenciar un proceso de transferencia de trabajo reproductivo entre mujeres de distinta clase social y grupo étnico, y por otro, trata de comprobar si se asiste a un proceso de segmentación dentro de los servicios vinculados a la reproducción social, así como a la etnización de determinadas modalidades. Los resultados del estudio permiten extraer una jerarquía alrededor de los servicios de proximidad, a la vez que muestran que las trabajadoras autóctonas e inmigrantes no se ubican en las mismas modalidades.

ABSTRACT. The concentration of immigrant women in reproductive services indicates a tripartite labour discrimination - based on social class, gender and ethnic group - in the receiving society. The article presents a general overview of the position of immigrant women in the Catalan labour market. The analysis evidences the transfer of reproductive work among women from different social class and ethnic group, and tries to identify a segmentation process of reproductive services and the ethnisation of certain levels or sectors. The results reveal a hierarchy of different levels, and show that indigenous and immigrant female workers really are not placed in the same sectors.

\footnotetext{
'Este trabajo recoge algunas de las principales conclusiones de mi Tesis Doctoral, presentada en el Departamento de Sociología de la UAB, y publicada bajo el titulo Mujer, inmigrante y trabajadora. La triple discriminación (Barcelona: Anthropos, 2003). Dicha Tesis Doctoral ha sido dirigida por la catedrática Carlota Solé Puig.

E-mail: sonia.parella@uab.es
}

Revista Internacional de Sociología (RIS)

Tercera Época, $N^{\circ} 36$, Septiembre-Diciembre, 2003, pp. 85-113. 
R I S

REVISTA INTERNACIONAL DE SOCIOLOGIA

No 36, Septiembre-Diciembre, 2003

SȮNIA PARELLA I RUBIO

\section{INTRODUCCIÓN}

El principal objetivo de este artículo es analizar el patrón laboral que sigue la migración internacional femenina en Cataluña, a partir del estudio de su fuerte concentración en los servicios de proximidad (o servicios de la vida diaria). Dichos servicios pueden definirse como aquellas actividades remuneradas destinadas a satisfacer las necesidades de las personas y de las familias que aparecen, en la actualidad, en la vida cotidiana de las sociedades occidentales (Torns, 1996). Algunos de estos servicios están fuertemente vinculados al cuidado de las personas (sobre todo de ancianos y enfermos) y otros tienen que ver con la esfera doméstica (limpieza y plancha a domicilio, etc.) (Torns, 1997; 1999a). Para las trabajadoras inmigrantes ${ }^{2}$ que llegan a la sociedad receptora, a la segregación laboral por razones de etnia se añade la discriminación se género, lo que permite explicar su sobreespecialización y hacinamiento en aquellas ramas del sector servicios fuertemente feminizadas y socialmente menos valoradas: los servicios de proximidad.

La necesidad de externalizar parte del trabajo reproductivo genera "nuevas" ocupaciones, caracterizadas por la precariedad, el desprestigio social, los bajos salarios, la falta de regulación y la invisibilidad. Se trata de empleos cuyo imaginario social les asocia a la baja estima social, el desprestigio y la descualificación. Justamente por este motivo no son absorbidos por la mujer autóctona; una mujer que ha adquirido un elevado nivel educativo en los últimos años y a la que el mercado de trabajo brinda mejores oportunidades laborales. El colectivo de mujeres autóctonas que han trabajado desde siempre como empleadas domésticas y que siguen desempeñando esta actividad en la actualidad, no sólo es insuficiente en cuanto a número de efectivos, sino que carece de relevo generacional. La falta de correspondencia entre oferta y demanda se traduce en la necesidad de reclutar a mujeres inmigrantes procedentes de los países periféricos para rellenar este vacío laboral. Es en este contexto de efecto "atracción" (pull) en el que debe situarse la creciente feminización de los flujos migratorios internacionales.

La feminización de los flujos migratorios que se da en Cataluña debe ser enmarcada en el proceso de terciarización que afecta a las grandes concentraciones urbanas de las sociedades occidentales. Dicho proceso da lugar a la expansión de puestos de trabajo poco cualificados y escasamente remunerados en el sector ser-

\footnotetext{
${ }^{2}$ A lo largo de estas páginas, el término "mujer inmigrante" se usa para hacer referencia a la figura social de la mujer procedente de países periféricos que ha protagonizado migraciones laborales hacia los países del Centro, con independencia de cuál sea su estatuto jurídico (irregular, regular, nacionalizada). Por lo tanto, este término no es sinónimo de "mujer extranjera", categoría jurídica y administrativa que incluye a toda persona que no haya nacido en la sociedad en la que reside, de forma temporal o permanente, y que carezca de la nacionalidad del país.
} 
vicios, directamente vinculados a la sustitución de las tareas domésticas atribuidas tradicionalmente a la mujer. Este incremento no sólo es el resultado de la nueva economía del conocimiento y del proceso de globalización, sino que se explica como respuesta a la demanda de una mano de obra que permita satisfacer las pautas de consumo y estilos de vida de las clases medias urbanas; sin olvidar los efectos del envejecimiento de la población y las necesidades reproductivas relacionadas con el nuevo estatus de las mujeres autóctonas que se incorporan al mercado de trabajo. Se trata de actividades intensivas en fuerza de trabajo, que no pueden "deslocalizarse" y que deben realizarse in situ (en el mismo lugar donde existe la demanda). Dichas actividades comprenden tanto ocupaciones poco cualificadas en el sector servicios (tales como guardias jurados para edificios de viviendas, empleados de restaurantes, acompañantes de perros, etc.), como los servicios de proximidad (empleados de limpieza a domicilio, canguros, etc.), cuya demanda no cesa de crecer (Sassen, 1984; 1993; 1994; 1998).

La posición laboral de la mujer inmigrante en la sociedad catalana y su concentración en los denominados "servicios de proximidad" nos revela la existencia de un mercado de trabajo estructurado a partir del género y la etnia; en el sentido de mostrar la segregación ocupacional de la mujer inmigrante en los puestos de trabajo situados en los lugares más bajos de la estructura ocupacional, como resultado de la confluencia de un triple proceso de discriminación (clase, género y etnia), junto al consiguiente fortalecimiento de una rígida división social dentro del propio colectivo femenino (entre mujeres autóctonas e inmigrantes). Pero, además, dentro de los servicios vinculados a la reproducción social también se detecta un proceso de segmentación en función de la etnia, puesto que son las actividades más precarias, más desreguladas, socialmente menos valoradas, con peores condiciones laborales y con un fuerte imaginario servil, las que son reservadas a la fuerza de trabajo extranjera. En definitiva, en palabras de Catarino y Oso, se asiste a «(...) la progresiva etnización de los servicios reproductivos» (2000: 2).

A lo largo de estas páginas nos detendremos, en primer lugar, en el análisis de cuáles son las principales causas del imparable aumento de la demanda de servicios de proximidad. A continuación, se muestra la segregación laboral a la que se enfrenta la mujer inmigrante en Cataluña, por razón de su sexo y de su etnia, a partir del análisis de distintas fuentes estadísticas disponibles que ponen de manifiesto su fuerte concentración en el servicio doméstico. Seguidamente, se recogen los obstáculos inherentes al desarrollo de los servicios de proximidad en Cataluña desde una perspectiva de género, en el contexto de un mercado de trabajo sexualmente segmentado y de una fuerte desregulación y desvalorización social de estas actividades. Tales obstáculos permiten entender por qué se recurre a la mujer inmigrante para emplearse en los puestos de trabajo que se crean en torno a los servicios de proximidad. El artículo culmina con una aproximación cualitativa a la estructura de la oferta de dichos servicios en Cataluña y a la iden- 


\section{RIS}

tificación de los procesos de etnización (o segmentación en función de la etnia) que se dan en su seno, a partir de la comparación de las posiciones que ocupan las trabajadoras autóctonas y las inmigrantes.

\section{LOS SERVICIOS DE PROXIMIDAD COMO RESPUESTA A NUEVAS NECESIDADES SOCIALES}

Efectivamente, la mercantilización del trabajo doméstico familiar siempre ha existido $^{3}$, de la mano de la figura de la criada o criado y del servicio doméstico tradicional, que se nutría principalmente de mujeres jóvenes de origen rural - procedentes del interior de Cataluña o bien del resto de España - que se empleaban en los hogares de las familias más adineradas. Lo que sí es nuevo es el contexto en el que surge el incremento masivo de la demanda actual, una demanda protagonizada por los sectores de población pertenecientes a las clases medias urbanas y que debe ser contextualizada a partir de los cambios sociodemográficos y económicos acontecidos en las últimas décadas en las sociedades occidentales. Estos cambios han impulsado importantes transformaciones en la familia y en la gestión de la vida cotidiana, sobre la base, principalmente, de la emancipación del colectivo de mujeres. Entre todas estas transformaciones destacan el envejecimiento de la población y el consiguiente incremento de las situaciones de dependencia y de demanda de servicios de cuidado ${ }^{4}$; la generalización de los hogares donde el padre y la madre trabajan a tiempo completo; el mayor número de hogares monoparentales; la progresiva tendencia hacia la dispersión geográfica de la familia; una nueva gestión del tiempo en el interior del núcleo familiar; y, por último, la crisis fiscal del Estado del Bienestar, en el marco de las corrientes neoliberales y del denominado pensamiento único que impera desde la década de los ochenta.

\footnotetext{
${ }^{3}$ Por mercantilización del trabajo doméstico familiar o trabajo doméstico remunerado, entendemos el desarrollo de las mismas tareas que incluye el trabajo reproductivo o doméstico familiar, pero desde una relación mercantil establecida entre la familia y asalariados externos (Colectivo IOÉ, 2001c: 42).

${ }^{4} \mathrm{Si}$ se cumplen los pronósticos de la UE, en el horizonte de 2020 es muy probable que el porcentaje de personas mayores de 65 años alcance el $21 \%$, según datos del EUROSTAT. En lo que se refiere a España y a Cataluña, las previsiones demográficas también apuntan hacia el aumento espectacular de las personas mayores de 65 años, tanto en términos absolutos como relativos. Aunque el proceso de envejecimiento se ha iniciado más tarde que en el resto de países europeos, se está desarrollando en la actualidad a un ritmo vertiginoso. Estudios demográficos prospectivos relativos a España, realizados por el INE basándose en los datos del censo de 1991, vaticinan que, en el año 2020, un $19,8 \%$ de la población superará los 65 años, de la cual, un $28,7 \%$ contará con más de 80 años.
} 
El proceso de externalización de parte del trabajo reproductivo por parte de las clases medias urbanas constituye, sin ningún género de dudas, el principal motor de la demanda de servicios de proximidad. Ante una serie de cambios demográficos, políticos, sociales y económicos que han ocurrido en los últimos años, la mujer autóctona se enfrenta a graves dificultades a la hora de compatibilizar su doble adscripción a la esfera productiva y reproductiva; mientras el hombre sigue sin implicarse suficientemente en las tareas doméstico-familiares. Es en este contexto en el que, por primera vez, se pone de manifiesto la importancia del trabajo reproductivo y éste pasa a convertirse en un problema que trasciende el ámbito privado y que afecta al conjunto de la sociedad. Sin embargo, aunque esta problemática empieza a incorporarse en la agenda política catalana, el escaso desarrollo de la política familiar (en especial, de las políticas de conciliación de la vida profesional y familiar) indica que la resolución del "conflicto", por el momento, sigue recayendo en las familias o, lo que es lo mismo, en las mujeres (Flaquer, 2000; Brullet, 2000; 2002).

El aumento de las tasas de actividad femenina en Cataluña ha sido espectacular en los últimos años, pasando de una tasa cercana al 30\% al finales de la década de los ochenta, a un 46,3\% en el primer trimestre del año 2002 (41,2\% en el caso de España). Este incremento, que se observa desde hace tiempo en los países nórdicos y del centro de Europa, ha empezado a implantarse recientemente (años noventa) en los países mediterráneos, así como también en Irlanda. De hecho, la tasa de actividad femenina presenta una gran variabilidad por edades, de modo que mientras casi un $75 \%$ de las mujeres entre 25 y 29 años son activas, las que tienen entre 50 y 54 años no alcanzan el $36 \%$ (frente a un $88,1 \%$ de tasa de actividad masculina en este tramo de edad), según datos de la EPA de 2000. Se asiste, pues, a una clara ruptura generacional. Ha sido la generación de mujeres catalanas de menos de 40 años las que han protagonizado una verdadera revolución, tanto en el terreno laboral, como en el reproductivo. Sin lugar a dudas, el auge de la enseñanza formal entre las mujeres es el instrumento clave para entender su inserción activa en la producción extradoméstica ${ }^{6}$.

En ausencia de un Estado "protector" al que transferir parte de las responsabilidades privadas de los cuidados y en el marco de una sociedad patriarcal que atribuye a la mujer prácticamente en exclusiva las tareas doméstico familiares, las mujeres autóctonas se enfrentan a graves dificultades a la hora de conciliar

\footnotetext{
${ }^{5}$ El análisis de las políticas familiares en la Comunidad Autónoma de Cataluña se recoge en una interesante investigación de Flaquer y Brullet (1999).

${ }^{6}$ Sin embargo, las mujeres con estudios no alcanzan los mismos niveles que sus homólogos masculinos en el mercado de trabajo, lo que constituye una fuente de gran frustración, tal como recogen Alberdi et al. (2000) en un estudio sobre las mujeres jóvenes en España.
} 
RIS

REVISTA INTERNACIONAL DE SOCIOLOCIA

No 36, Septiembre-Diciembre, 2003

SÒNIA PARELLA I RUBIO

su vida familiar y laboral. En definitiva, a la vez que aumentan las demandas de cuidado, el tiempo disponible de las mujeres, en lo referente a su condición de principales cuidadoras informales en el seno de las familias, está disminuyendo y va a disminuir en los próximos años, consecuencia tanto de un efecto de cohorte como el resultado de la incorporación femenina en el mercado laboral. Las estrategias individuales para lograr tal conciliación son diversas y suponen un elevado coste, especialmente para las mujeres, tanto en el terreno emocional - estrés, disminución de la fecundidad, sentimiento de culpabilidad, etc.económico - pérdida de poder adquisitivo cuando se recurre al mercado, o profesional - inactividad femenina, doble presencia, obstáculos a la promoción laboral de las mujeres, etc.

Entre las distintas estrategias adoptadas ocupa un lugar destacado, sobre todo entre las familias de clase media en la que ambos miembros de la pareja son laboralmente activos, la mercantilización de parte de las actividades no remuneradas. Ante la exigencia de competencia profesional para hombres y mujeres y la no valoración social del trabajo reproductivo, determinadas labores reproductivas también son rechazadas por algunas mujeres autóctonas que cuentan con ingresos económicos suficientes. En consecuencia, dichas tareas son transferidas a otras mujeres, ya sea a través del recurso a mujeres inmigrantes, principalmente, o bien de mujeres autóctonas de clase baja y con escaso nivel educativo, a las que el mercado de trabajo no ofrece otras oportunidades laborales ${ }^{7}$.

Lamentablemente, esta estrategia prácticamente no altera los patrones de conducta tradicionales según el género. La externalización de parte del trabajo reproductivo está muy lejos de significar que la mujer que trabaja fuera del hogar se descarga de sus responsabilidades domésticos familiares, contrariamente a lo que pasa en el caso de los miembros masculinos del hogar. Aunque entre las generaciones más jóvenes y con mayor nivel educativo se observan mayores cotas de igualdad entre hombres y mujeres en la esfera reproductiva y una separación de roles menos rígida, todavía queda mucho camino por recorrer. Las nuevas generaciones masculinas son conscientes de que deben "colaborar" en el hogar; sin embargo, tal predisposición, muy a menudo, o bien forma parte de una actitud condescendiente que no cuestiona la división sexual del trabajo, o bien se limita

\footnotetext{
${ }^{7}$ Tal externalización de parte del trabajo reproductivo está muy lejos de significar que la mujer que trabaja fuera del hogar se descargue totalmente de sus responsabilidades doméstico familiares, análogamente a lo que ocurre generalmente en el caso de los miembros varones del hogar. Por el contrario, habitualmente sigue siendo ella la que supervisa las tareas que son delegadas, la que se ocupa de los quehaceres vinculados a la organización, gestión y responsabilidad del hogar/familia, del trabajo de mediación entre el hogar y las instituciones públicas y privadas dedicadas a la reproducción física y social de los individuos, así como de la gestión afectiva y relacional de los miembros de la familia (fiestas de aniversario, visitar enfermos, etc.).
} 
a ofrecer una "ayuda" puntual, de modo que es la mujer la que organiza y señala cuáles son las tareas a desempeñar y cómo deben realizarse ${ }^{8}$.

Pero la cada vez más extendida pauta de externalizar parte del trabajo reproductivo no se explica únicamente por la ausencia de los hombres en la esfera reproductiva. Entre los sectores de la población con más nivel educativo se asiste, paralelamente, al proceso de mercantilización de la cultura y del ocio, a una nueva gestión del tiempo en el interior del núcleo familiar, y a un nuevo concepto de "calidad de vida", basado en una valoración sin precedentes del tiempo para el ocio y el tiempo para uno/a mismo/a, al que ni hombres ni mujeres están dispuestos a renunciar (Gregson y Lowe, 1994). Es en este sentido que externalizar el trabajo reproductivo supone una estrategia con la que las parejas "compran" tiempo, que invierten en gratificación afectiva, en la relación de pareja, etc. La disponibilidad y los esfuerzos que requiere una carrera profesional permite explicar que el tiempo sea un recurso cada vez más valorado y su "compra" una tendencia al alza' ${ }^{9}$. Los servicios de proximidad son, pues, reveladores de la diversificación de las relaciones interpersonales, como consecuencia de la individualización de los modos y estilos de vida característicos del proceso de urbanización (Bonnet y Bernard, 1998).

En este contexto, aparecen "nuevos" espacios para la ocupación de mujeres inmigrantes, que van afianzando una internacionalización de la reproducción que permite a las mujeres de los países del Centro ascender en la escala ocupacional y social, gracias a que las mujeres procedentes de los países Periféricos se sitúan en la base de dicha escala. Es así como las mujeres inmigrantes configuran un nuevo "ejército de reserva" en un mercado de trabajo que opera a escala internacional. El empleo de mujeres inmigrantes para realizar las tareas reproductivas preserva el hogar tradicional patriarcal, amortigua el conflicto dentro de la pareja, a la vez que "tranquiliza" la conciencia de la mujer empleadora y refuerza su identidad como ama de casa competente (Momsen, 1999; Anderson, 2000). Esta situación permite identificar un trasvase de desigualdades de clase y

\footnotetext{
${ }^{8} \mathrm{El}$ informe Mujeres en cifras 1996-2000, elaborado por el Instituto de la Mujer (IMU), muestra que mientras la mujer dedicó en el año 2001 cuatro horas diarias a las tareas domésticas (3 horas y 58 minutos), el hombre ha invertido cinco veces menos (44 minutos). Si se comparan estos datos con los de 1996, se observa que las diferencias no son muy notables: la mujer dedicaba a las tareas reproductivas una media de 4 horas y 24 minutos, frente a los 37 minutos de los varones. En definitiva, el hombre sólo ha aumentado en 7 minutos su dedicación a este menester a lo largo de 6 años (IMU, 2002).

${ }^{9}$ En algunos casos, la externalización de parte del trabajo reproductivo (las tareas de limpieza, por ejemplo) persigue no sólo la obtención de mayor tiempo libre o una mayor dedicación a la profesión, sino poder invertir más tiempo en otras tareas reproductivas especialmente valoradas, como, por ejemplo, ocuparse de los hijos.
} 
RIS

REVISTA INTERNACIONAL DE SOCIOLOGIA

№ 36, Septiembre-Diciembre, 2003

SÒNIA PARELLA I RUBIO

etnia dentro del propio colectivo de mujeres, de modo que se configura una grieta creciente entre una minoría de mujeres cualificadas, que residen en los países del Centro, y una mayoría de trabajadoras proletarizadas, procedentes de la Periferia, de una clase social y de una etnia distintas, que ejercen tareas propias de "servidoras".

\section{LAFEMINIZACIÓNDE LOS FLUJOSMIGRATORIOSINTERNACIONALES HACIA CATALUÑA Y SUS PAUTAS DE INSERCIÓN LABORAL}

Según datos de la Comisión Interministerial de Extranjería, son un total de 280.167 los residentes extranjeros en Cataluña a 31 de diciembre del año 2001. Esta cifra supone un total de 44,69 residentes extranjeros por cada 1000 habitantes. La feminización de la inmigración es un rasgo también característico de Cataluña, con un $40,9 \%$ de mujeres dentro del cómputo total de extranjeros (el porcentaje de mujeres para el conjunto de España es de casi el 45,0\%). La proporción de mujeres varía según el continente de procedencia, tal como nos muestra la tabla 1 , de modo que, mientras los europeos presentan una distribución prácticamente igualitaria de hombres y mujeres, en África y Asia predomina un perfil de inmigración masculina —en mucha menor medida en el continente asiático-; por contra, en los países latinoamericanos existe una marcada feminización de los flujos migratorios.

No existe una única explicación para dar cuenta de la diferente composición por sexo de los distintos colectivos, puesto que intervienen tanto factores rela-

Tabla 1.

Porcentajes por sexo de la población de nacionalidad entranjera residente en Cataluña según continente (2001).

\begin{tabular}{lcc}
\hline Continente & \% Hombres & \% Mujeres \\
\hline Espacio Económico Europeo & 54,67 & 45,33 \\
Resto de Europa & 56,90 & 43,10 \\
África & 68,24 & 31,76 \\
América del Norte & 53,00 & 47,00 \\
Iberoamérica & 42,96 & 57,04 \\
Asia & 67,23 & 32,77 \\
Oceanía & 56,67 & 43,33 \\
Total 2001 & 59,10 & 40,90 \\
\hline
\end{tabular}

Fuente: Comisión Interministerial de Extranjería (2002), Anuario Estadistico de Extranjería. 
cionados con las sociedades de origen como con las de destino. En el caso de los residentes europeos, la situación de equilibrio se explica por tratarse mayormente de matrimonios jubilados que establecen su residencia en la costa tarraconense. Para la migración africana, la estigmatización del éxodo rural femenino que se da en algunas sociedades de origen se traduce en una mayor proporción de hombres. Pero, sin lugar a dudas, el factor más sustancial a la hora de interpretar la feminización de los flujos son los condicionantes del mercado laboral en la sociedad de destino. En este sentido, la notoria feminización de los flujos migratorios procedentes de los países latinoamericanos y, en menor medida, la de los flujos originarios de la Europa del Este y Asia (sobre todo para el caso de Filipinas), está intimamente relacionada con los factores pull (atracción); a saber, la demanda de trabajadoras inmigrantes para trabajar en el servicio doméstico.

La distribución de los residentes por sexo y por provincias se refleja en la tabla 2. La feminización de la migración es especialmente relevante en el caso de la provincia de Barcelona, que concentra casi el $75 \%$ del total de mujeres con

Tabla 2.

Mujeres extranjeras en Cataluña. Distribución por provincia.

\begin{tabular}{lccc}
\hline Provincia & Mujeres & $\begin{array}{c}\text { \% Mujeres } \\
\text { (respecto total extranjeros) }\end{array}$ & Total \\
\hline Barcelona & 85.000 & 41,31 & 206.395 \\
Girona & 16.499 & 41,50 & 40.322 \\
Lleida & 3.852 & 32,71 & 11.984 \\
Tarragona & 8.593 & 40,41 & 21.466 \\
Total Cataluña & 113.944 & 40,90 & 280.167 \\
Total España & 494.843 & 44,62 & 1.109 .060 \\
\hline
\end{tabular}

Fuente: Comisión Interministerial de Extranjería (2002), Anuario Estadistico de Extranjería 2001

permiso de residencia en Cataluña, y un $41,31 \%$ de mujeres respecto al total de extranjeros. Esta marcada feminización se debe a la fuerte concentración de la demanda de servicio doméstico en las zonas urbanas (la ciudad de Barcelona y su Área Metropolitana).

La ciudad de Barcelona constituye un auténtico foco de atracción para la inmigración femenina. En ella residen, si ponemos en relación los datos del Padrón de Habitantes del Ayuntamiento de Barcelona con las cifras referentes a los permisos de residencia provinciales, casi el $56 \%$ del total de mujeres extranjeras 
R IS

REVISTA INTERnacional ue SOCIOLOCia

No 36, Septiembre-Diciembre, 2003

SÒNIA PARELLA I RUBI0

de la provincia de Barcelona y cerca del $42 \%$ de las que residen en Cataluña. Los colectivos más feminizados son los procedentes de América Central y del Sur (véase la tabla 3). También merece ser destacada la proporción de mujeres originarias del sureste asiático y de los países de la Europa del Este.

En cuanto al nivel de instrucción de la población extranjera femenina afincada en la ciudad de Barcelona, según datos del Ayuntamiento de Barcelona a enero de 2002, en término medio, éste es elevado y no presenta notorias diferencias con respecto al de los hombres extranjeros. Sin embargo, sí se detectan disparidades entre las mujeres según el continente de procedencia. De ese modo, tal como muestra la tabla 4, entre las mujeres de origen africano predominan las que cuentan con estudios primarios, sobre todo para las originarias del norte de África y del Magreb. En el caso de las mujeres latinoamericanas existe una mayor proporción de inmigrantes con estudios medios y superiores. Las mujeres asiáticas presentan un nivel educativo elevado, similar al de las americanas, salvo en el caso de las originarias de Asia Central, con más de un $70 \%$ de mujeres con

Tabla 3.

Extranjeros residentes en la ciudad de Barcelona según sexo y áreas geográficas de origen (Enero 2002).

\begin{tabular}{lccc}
\hline Área Geográfica & Número extranjeros & \% Extranjeros & \% Mujeres * \\
\hline TOTAL & 98.705 & 100.0 & 48,2 \\
Oriente Medio & 1.147 & 1,0 & 34,3 \\
Asia Central & 11.604 & 10,2 & 23,9 \\
Sureste asiático & 4.302 & 3,8 & 57,1 \\
Norte de África y Magreb & 11.291 & 9,9 & 35,1 \\
África subsahariana & 2.244 & 2,0 & 35,3 \\
África central y meridional & 358 & 0,3 & 44,7 \\
América central & 9.003 & 7,9 & 63,4 \\
América del sur & 48.528 & 42,6 & 54,8 \\
Europa central y oriental & 6.006 & 5,3 & 48,2 \\
Resto de países** & 19.326 & 17,0 & 47,1 \\
\hline
\end{tabular}

* Respecto del total de extranjeros de la misma área geográfica

** Incluye los países de la UE, Andorra, Islandia, Liechtenstein, Malta, Mónaco, Noruega, San Marino, Suiza, Ciudad del Vaticano, Chipre, Estados Unidos, Canadá, Japón y Oceania

Fuente: Departament d'Estadística. Ajuntament de Barcelona. La població estrangera a Barcelona. 
Tabla 4.

Mujeres extranjeras residentes en Barcelona según área geográfica de origen, y nivel de estudios (Enero 2002).

\begin{tabular}{lcccc}
\hline Àrea geográfica & $\begin{array}{c}\text { Mujeres } \\
\text { extranjeras }\end{array}$ & $\begin{array}{c}\text { \% Estudios } \\
\text { primarios }\end{array}$ & $\begin{array}{c}\text { \% Estudios } \\
\text { secundarios }\end{array}$ & $\begin{array}{c}\text { \% Estudios } \\
\text { superiores }\end{array}$ \\
\hline Total & 47.572 & 41,0 & 29,2 & 28,0 \\
Oriente Medio & 319 & 32,9 & 33,2 & 32,6 \\
Asia Central & 2.141 & 71,0 & 16,6 & 10,3 \\
Sureste asiático & 2.139 & 50,3 & 24,4 & 21,7 \\
Norte de África y Magreb & 3.118 & 77,8 & 13,8 & 6,6 \\
África subsahariana & 678 & 68,1 & 22,3 & 7,1 \\
África central y & 145 & 45,5 & 33,8 & 15,2 \\
meridional & 4.988 & 47,5 & 28,5 & 21,6 \\
América central & 23.430 & 38,5 & 33,9 & 25,9 \\
América del sur & 2.487 & 32,8 & 26,7 & 39,6 \\
Europa central y oriental & 8.127 & 19,9 & 27,4 & 51,0 \\
\hline Resto países* & & &
\end{tabular}

*Incluye los países de la UE, Andorra, Islandia, Liechtenstein, Malta, Mónaco, Noruega, San Marino, Suiza, Ciudad del Vaticano, Chipre, Estados Unidos, Canadá, Japón y Oceania

Fuente: Departament d'Estadística. Ajuntament de Barcelona. La població estrangera a Barcelona.

estudios primarios. El colectivo de mujeres con un nivel educativo más elevado son sin lugar a dudas, las procedentes de Europa Central y del Este, con casi un $40 \%$ de mujeres con estudios universitarios.

Las estadísticas oficiales no ofrecen un conocimiento suficientemente preciso de la actividad laboral de los extranjeros que residen en España y Cataluña. La estadística de permisos de Trabajo a extranjeros ha sido hasta ahora la fuente más utilizada, aunque estos datos sólo recogen el número de total de extranjeros en situación legal, adscritos al Régimen General, lo que excluye a los irregulares, así como a los inmigrantes en situación legal acogidos al Régimen Comunitario. En Cataluña, tal como muestra la tabla 5 , están en vigor 53.804 permisos de trabajo a 31 de diciembre de 1999. Más de la mitad de los permisos (54,6\%) se concentran en el sector servicios. Casi el $70 \%$ del total de los permisos en vigor corresponden a la provincia de Barcelona (36.430), de los que aproximidamente el $64 \%$ son para el sector servicios. De los 53.804 permisos en vigor para el conjunto de Cataluña, 
R I S

REVISTA INTERNACIONAL DE SOCIOLOCÍA

No 36, Septiembre-Diciembre, 2003

SÒNIA PARELLA I RUBIO

Tabla 5 .

Trabajadores extranjeros con permisos de trabajo en vigor según sector de actividad y sexo, a 31 de diciembre de 1999. Cataluña.

\begin{tabular}{lccccccccc}
\hline & & & & \multicolumn{5}{c}{ No } \\
& Total & Agrario & Industria & Construcción & Servicios clasificados & Hombres & Mujeres \\
\hline Total & 199.753 & 42.256 & 14.809 & 18.699 & 116,814 & 7.175 & 130.340 & 69.413 \\
España & & & & & & & & & \\
Cataluña & 53.804 & 6.807 & 6.580 & 6.766 & 29.371 & 4.280 & 36.066 & 17.738 \\
Barcelona & 36.430 & 2.429 & 4.372 & 4.281 & 23.280 & 2.068 & 21.981 & 14.449 \\
Girona & 9.428 & 1.429 & 1.262 & 1.449 & 3.691 & 1.597 & 7.472 & 1.956 \\
Lleida & 3.801 & 1.609 & 625 & 412 & 843 & 312 & 3.205 & 596 \\
Tarragona & 4.145 & 1.340 & 321 & 624 & 1.557 & 303 & 3.408 & 737 \\
\hline
\end{tabular}

Fuente: Estadistica de Permisos de Trabajo a Extranjeros (MTSS).

un tercio (17.738) pertenece a mujeres. Para el caso de la provincia de Barcelona, la proporción de mujeres dentro del total de permisos de trabajo en vigor alcanza el $66 \%$. No es de extrañar tal acusada feminización de la fuerza de trabajo en la provincia de Barcelona, puesto que es en la zona urbana del Área Metropolitana de Barcelona donde se concentra la mayor parte de la demanda de servicios de proximidad.

Otra fuente estadística de carácter oficial procede del sistema de Seguridad Social y recoge las personas extranjeras que están dadas de alta en algunos de sus regímenes. El alta en la Seguridad Social no siempre refleja la actividad económica real que se desempeña (puede cotizarse en un régimen y no tener empleo o estar trabajando irregularmente en otro) y, obviamente, también deja al margen las personas empleadas en la economía sumergida. Según la estadística de trabajadores extranjeros en alta en la Seguridad Social, Cataluña cuenta con el $27 \%$ de los extranjeros afiliados para el conjunto de España, con 164.294 efectivos en mayo del 2002. Tal como se desprende de la tabla 6, el $31,6 \%$ de los afiliados extranjeros en Cataluña son mujeres (51.898) y este porcentaje alcanza casi el $35 \%$ para la provincia de Barcelona ${ }^{10}$. De ese modo, Catalunya proporciona casi el $25 \%$ de las mujeres extranjeras afiliadas para el conjunto de España. Si

\footnotetext{
${ }^{10} \mathrm{La}$ diferencia entre el número de mujeres extranjeras afiliadas a la Seguridad Social (51.898) y el número de permisos de trabajo concedidos a trabajadoras extranjeras (17.738), se explica, a parte de por la diferencia cronológica de casi tres años que existe entre ambos datos, por el hecho de que las estadísticas de permisos de trabajo no recogen a las mujeres acogidas al Régimen Comunitario.
} 
Tabla 6.

Trabajadores extranjeros afiliados en alta laboral según sexo.

\begin{tabular}{lcccccc}
\hline & \multicolumn{3}{c}{ Valores absolutos } & \multicolumn{3}{c}{ Distribuciones porcentuales } \\
\cline { 2 - 7 } & Ambos sexos & Varones & Mujeres & Ambos sexos & Varones & Mujeres \\
\hline $\begin{array}{l}\text { Total España } \\
\text { (a 31/12/2001) }\end{array}$ & 606.967 & 398.553 & 208.414 & 100,0 & 100,0 & 100,0 \\
Cataluña & 164.294 & 112.373 & 51.898 & 27,0 & 28,2 & 24,9 \\
Barcelona & 116.063 & 76.137 & 39.911 & 19,1 & 19,1 & 19,1 \\
Girona & 21.984 & 16.087 & 5.893 & 3,6 & 4,0 & 2,8 \\
Lleida & 10.630 & 8.580 & 2.049 & 1,7 & 2,1 & 1,0 \\
Tarragona & 15.617 & 11.569 & 4.045 & 2,6 & 2,9 & 1,9 \\
\hline
\end{tabular}

Fuente: Elaboración propia a partir de: Estadistica de trabajadores extranjeros afiliados en alta laboral (MTAS) (Mayo, 2002).

ponemos en relación el número de extranjeras afiliadas con el total de extranjeras residentes en Cataluña, obtenemos una tasa de actividad de alrededor del $46 \%$ para este colectivo, cifra que debe ser matizada, puesto que no refleja la fuerte incidencia del empleo informal o sumergido, así como tampoco el volumen de mujeres desempleadas.

En Cataluña, de un total de 164.294 trabajadores extranjeros afiliados en alta laboral (según datos del mes de mayo de 2002), cerca del 7,5\% están afiliados al Régimen Especial de Empleados de Hogar. Aunque no se dispone de datos que permitan cruzar el sexo y el régimen para los trabajadores extranjeros afiliados, se estima que el servicio doméstico da empleo a prácticamente la mitad de las mujeres no comunitarias que cotizan a la Seguridad Social, por lo que constituye, sin lugar a dudas, la "puerta de entrada" en el mercado de trabajo para la mayoría de trabajadoras extranjeras (Colectivo IOÉ, 2001b).

De ese modo, si se añade la perspectiva de género al fenómeno de la estratificación del mercado de trabajo a partir de la etnia, se constata que, aunque el conjunto de la población inmigrada se vea abocada a las ocupaciones de menor estatus social, menor remuneración y peores condiciones laborales, son las mujeres inmigrantes las que ocupan el último escalafón: el servicio doméstico (sin olvidar la prostitución) ${ }^{11}$. Las mujeres inmigrantes constituyen una especie de "subseg-

\footnotetext{
"Aunque no se dispone de datos al respecto, son muchas las mujeres inmigrantes que encuentran el servicio doméstico como una opción desagradable, dificil o mal pagada, sobre todo entre
} 
mento" del mercado de trabajo femenino, ya de por sí más restringido que el de los hombres. El abanico de oportunidades laborales de las mujeres inmigrantes es mucho más reducido que el que se ofrece a sus homólogos masculinos: los trabajadores inmigrantes. La confinación de la mujer inmigrante en el servicio doméstico se fundamenta en la confluencia de las desigualdades de género, clase y etnia, responsable de que se las reciba en la sociedad receptora bajo el prejuicio de que sólo están capacitadas para realizar estas tareas; por cuanto se asume que su condición de mujeres les confiere este tipo de cualificaciones tácitas o informales, independientemente de su nivel de estudios y cualificación.

Por todo lo apuntado, a pesar de la pluralidad de cronologías, circunstancias y orígenes geográficos, económicos, sociales y culturales que, sin duda, presentan las mujeres inmigrantes en Cataluña (que no son objeto de análisis en este artículo), así como la heterogeneidad en sus trayectorias laborales, existen factores estructurales que influyen en todas ellas y que las relegan a un "nicho laboral" muy concreto del mercado de trabajo: el servicio doméstico. La mujer inmigrante acepta esta posición en la estructura ocupacional debido a su "nivel de aceptación" de condiciones de trabajo inferior al de la mujer autóctona (Villa, 1990). En el caso de la mujer trabajadora inmigrante, la necesidad imperiosa de percibir ingresos con los que poder ahorrar y mantener a sus familiares dependientes, la falta de redes de apoyo económico en la sociedad receptora - a diferencia de las mujeres autóctonas, que cuentan con sus familias-, un proyecto migratorio de retorno, la influencia de las redes étnicas en el proceso de reclutamiento y la percepción de enfrentarse a un mercado de trabajo segmentado según la etnia y el género, las conduce a rebajar el nivel por debajo del cual considerarían sus oportunidades de empleo como "socialmente" inaceptables, independientemente de su cualificación. A tenor del elevado nivel educativo que, por término medio, presentan las mujeres inmigrantes, su inserción laboral en el servicio doméstico genera frecuentes situaciones de "inconsistencia de estatus".

\section{LOS “SERVICIOS DE PROXIMIDAD” DESDE UNA PERSPECTIVA DE GÉNERO}

Los servicios de proximidad, que son una nueva denominación del servicio doméstico, se han convertido en una ocupación con futuro para las mujeres y constituyen uno de los principales focos de interés en los debates sobre las nuevas profesiones y la promoción de la creación de empleo (Fraise, 2000). Autores como Esping-Andersen (1999) postulan por el desarrollo de estos servicios, tanto desde

las mujeres dominicanas, ecuatorianas o nigerianas, y que optan por la industria sexual como una opción más "interesante". 
el Estado como desde el mercado, no sólo para impulsar la creación de empleo, sino también como estrategia "desfamiliarizadora", que permita reducir la dependencia funcional entre los miembros de la familia y, de ese modo, favorecer la natalidad y la carrera profesional de las mujeres.

El inmenso potencial de creación de empleo alrededor de estas actividades queda ampliamente demostrado en un estudio del Departament de Treball de la Generalitat de Cataluña (2001), a través de la Enquesta a les llars [hogares] de Cataluña $^{12}$. De la citada investigación se desprende que la mayor parte de las necesidades sociales vinculadas a los servicios de proximidad se resuelven a través de la autoproducción (en más de un $75 \%$ por término medio, salvo en el caso de las reparaciones del hogar, con sólo el 12,5\%). Sin embargo, a tenor del grado de insatisfacción que manifiestan los encuestados, se estima que alrededor del $20 \%$ de los hogares catalanes pueden ser demandantes potenciales de servicios a las personas y a los hogares; en especial, en todo lo que se refiere al cuidado de personas dependientes y a la limpieza y cuidado del hogar, con niveles de insatisfacción que sobrepasan el 10\%. A partir del cálculo del impacto de la demanda efectiva insatisfecha futura de estos servicios (la demanda insatisfecha no incluye la cubierta por el trabajo no declarado), el estudio estima que podrán crearse más de 200.000 puestos de trabajo a tiempo completo (tabla 7 ).

Sin embargo, una primera mirada a los servicios de proximidad desde una perspectiva de género, concretamente a los ámbitos denominados "servicios a domicilio" y "cuidado de niños", revela que es cuestionable que la mera creación de puestos de trabajo garantice que éstos sean de calidad. Tal como concluye Tezanos (2001:158), el debate ya no debe situarse exclusivamente en torno a si hay o no hay empleo, sino en analizar si los nuevos puestos de trabajo creados son capaces de garantizar condiciones mínimas de bienestar social, de calidad de vida y de expectativas favorables de futuro. Lejos de ser así, el crecimiento de estas ocupaciones eminentemente femeninas puede traducirse en el reforzamiento de la situación de discriminación y de segregación laboral de la mujer en el mercado de trabajo, de modo que se conviertan en un ghetto femenino - para mujeres inmigrantes y mujeres con bajos niveles educativos y escasos recursos económicos- y se refuerce todavía más la repartición sexuada de la ocupación, así como las desigualdades de clase y de etnia (Torns, 1997; 1999b).

Tradicionalmente, y también en la actualidad, este tipo de servicios han sido y son dispensados desde el servicio doméstico, ya sea mediante una relación formalizada, ya sea bajo formas de economía sumergida. Desde el momento que estas actividades pasan a engrosar los "nuevos yacimientos de empleo", se supone que se asiste a un cambio en la relación laboral que vincula a quien presta el ser-

\footnotetext{
${ }^{12}$ Dicho estudio ha sido elaborado por la Fundació CIREM.
} 
RIS

REVISTA INTERNACIONAL DE SOCIOLOCIA

№36, Septiembre-Diciembre, 2003

SÒNIA PARELLA I RUBIO

Tabla 7.

Potencial de creación de ocupación en los servicios habituales

a las personas y hogares.

\begin{tabular}{lcc}
\hline & $\begin{array}{c}\text { Demanda efectiva } \\
\text { insatisfecha futura para } \\
\text { servicios habituales a } \\
\text { personas/hogares } \\
\text { (\% sobre el total de } \\
\text { hogares pertinente) }\end{array}$ & $\begin{array}{c}\text { Estimación de ocupación } \\
\text { en ETC* de la demanda } \\
\text { efectiva insatisfecha }\end{array}$ \\
\hline Atención a personas dependientes & 43,2 & 11.780 \\
Limpieza y cuidado del hogar & 32,9 & 67.212 \\
Limpieza y cuidado de la ropa & 26,0 & 23.620 \\
Compra diaria & 21,4 & 19.429 \\
Reparaciones del hogar & 7,1 & 1.285 \\
Traslado de los niños a la escuela & 19,1 & 6.561 \\
Atención de los niños mediodía & 17,2 & 8.872 \\
Guarda niños en horario laboral & 22,3 & 67.023 \\
TOTAL & & 205.782 \\
\hline
\end{tabular}

* Para el cálculo del Equivalente a Tiempo Completo (ETC) se ha estimado un número de horas anuales para servicio y hogar que oscila entre las 16 horas para reparaciones y las 975 para guarda habitual de niños, así como una jornada laboral de 1.848 horas.

Fuente: Fundació CIREM, “Enquesta a les llars". Citado en: Generalitat de Catalunya (2001: 41).

vicio con el usuario; de modo que se pasa del régimen de laboralidad "especial" del servicio doméstico, en el que el usuario ejerce de empleador directo, a una laboralidad "común" entre una empresa de "servicios" y la persona que realiza el servicio, convirtiéndose el usuario en un mero cliente de la empresa. Este cambio jurídico tiene importantes repercusiones para las personas que prestan los servicios, puesto que les permite acceder a todas las prestaciones sociales que entraña el régimen general de la Seguridad Social (Pérez del Río, 1998).

Sin embargo, tal como bien señala la socióloga Teresa Torns (1997; 1999b), no es suficiente convertir estas actividades en una relación laboral "común" para que estos servicios generen empleos de calidad, sean valorados y prestigiados socialmente y superen los imaginarios de servilismo asociados a los tradicionales "servidores domésticos". Efectivamente, estas nuevas actividades surgen a finales del siglo XX, en un contexto que tiene aparentemente poco que ver con el servicio doméstico feudal o burgués. Son las "nuevas demandas" de las familias las que se utilizan para potenciar nuevas ocupaciones. A pesar de la enorme potencialidad de creación de empleo de los servicios de proximidad (desde una óptica cuantitativa), la realidad demuestra que la calidad de las ocupaciones creadas es baja, el estatus profesional y el reconocimiento 
jurídico indefinido, y el empleo inestable (Cachón, 1997). Recogiendo las palabras de la filósofa francesa Geneviève Fraise, estas actividades se mueven en la ambivalencia, al designar «(...) el lugar de una mutación de la organización del trabajo entre la gratuidad y el salario, entre la intimidad y la publicidad, entre la emancipación de las mujeres y la tradición de la función femenina...» (2000: 229).

Ante unos potenciales consumidores/usuarios que, o bien tienen problemas de solvencia económica (piénsese en los pensionistas jubilados), o bien, por motivos culturales, se muestran reticentes a pagar precios elevados por recibir prestaciones que están tan sumamente devaluadas, se potencia la expansión de las modalidades más baratas de los servicios de proximidad, cuyo menor coste se consigue mediante una desregulación "excesiva" de las condiciones de empleo (Fundació CIREM, 1999). Al tratarse de actividades intensivas en fuerza de trabajo, que habitualmente se ejecutan dentro del ámbito privado del hogar, la mayoría de estos nuevos empleos, o bien adquieren la modalidad del servicio doméstico tradicional (régimen de dependencia persona a persona), tanto declarado como no declarado, o bien de empleos "atípicos" en empresas privadas de servicios, a cambio de ínfimos salarios y peores condiciones laborales, muy a menudo dentro de la economía informal. Es así como el inmenso potencial de creación de ocupación alrededor de los servicios de proximidad se concreta, en ausencia de intervención del sector público, en puestos de trabajo de pésima calidad. Ello es causa y a la vez consecuencia de su flagrante feminización, en el contexto de un mercado de trabajo ya de por sí estructurado a partir de las desigualdades de género.

En definitiva, según los postulados de Esping-Andersen (1993), el potencial de creación de nuevo empleo de los servicios de proximidad en la UE puede concretarse en dos estrategias distintas. $\mathrm{O}$ bien se sigue el modelo norteamericano y se potencia a gran escala el sector privado de consumo, a través de la creación de puestos de trabajo mal remunerados e inestables que permitan hacer frente a los obstáculos arriba mencionados; o bien el sector público interviene de forma directa, por medio de un Estado del Bienestar (ya sea ofreciendo directamente servicios públicos, o financiando servicios privados) que permita configurar puestos de trabajo de mayor calidad, tal como ha ocurrido en el norte de Europa (en los países escandinavos). Tanto en un modelo como en el otro, los puestos de trabajo tienden a estar desproporcionadamente ocupados por mujeres e inmigrantes. Si se opta por el modelo norteamericano, allí donde los costes salariales sean elevados, el sector de los servicios de proximidad crecerá principalmente sobre la base del trabajo por cuenta propia o del empleo irregular, tal como es el caso de España y del resto de los países del sur de Europa (Esping-Andersen, 1996).

La mencionada encuesta a los hogares realizada en Cataluña permite obtener datos detallados sobre la demanda de servicios al hogar satisfecha mediante trabajo no declarado. Los resultados revelan que, hoy en día, más de 100.000 personas están trabajando en la economía informal realizando estas actividades, lo que podría convertirse en casi 40.000 puestos de trabajo a tiempo completo (tabla 8 ). 
RIS

REVISTA INTERNACIONAL DE SOCIOLOCIA

№ 36, Septiembre-Diciembre, 2003

SÒNIA PARELLA I RUBIO

Tabla 8.

Dimensión del trabajo no declarado en la prestación de servicios habituales a las personas y al hogar.

\begin{tabular}{lcc}
\hline & $\begin{array}{c}\text { Uso de trabajo no } \\
\text { declarado sobre total uso } \\
\text { servicios externos } \\
\text { remunerados \% }\end{array}$ & $\begin{array}{c}\text { Estimación ocupación } \\
\text { en ETC* del trabajo } \\
\text { remunerado no } \\
\text { declarado }\end{array}$ \\
\hline Atención a personas dependientes & 68,9 & 1.936 \\
Limpieza y cuidado del hogar & 72,5 & 22.069 \\
Limpieza y cuidado de la ropa & 46,2 & 545 \\
Compra diaria & 20,0 & 91 \\
Reparaciones del hogar & 24,9 & 3.778 \\
Traslado de los niños a la escuela & 7,4 & 241 \\
Atención de los niños mediodía & 4,8 & 772 \\
Guarda niños en horario laboral & 29,1 & 9.620 \\
TOTAL & & 39.002 \\
\hline
\end{tabular}

* Para el cálculo del Equivalente a Tiempo Completo (ETC) se ha estimado un número estimado de horas anuales para servicio y hogar que oscila entre las 16 horas para reparaciones y las 975 para guarda habitual de niños y una jornada laboral de 1.848 horas.

Fuente: Fundació CIREM, "Enquesta a les llars". Citado en: Generalitat de Catalunya (2001: 41).

Pero no todos los obstáculos son económicos. Otra dimensión no menos importante es el hecho de que muchos de los servicios de proximidad, lejos de tratarse de nuevas ocupaciones, suponen simplemente la externalización de actividades que desde siempre se han realizado - y siguen realizándose- en la esfera reproductiva, de manera invisible y en absoluto valorada ni económica ni socialmente, o bien dentro de la modalidad de criado(a)s (Torns, 1995; 1997; 1999b). La servidumbre del siglo XIX ya sufría las ambigüedades de la doble dependencia mercantil y doméstica y los actuales servicios de proximidad no se han desprendido de ella. Justamente por este motivo, los servicios asociados a la vida cotidiana (tareas domésticas, atención de ancianos y personas dependientes, cuidado de niños) están condenados a una fuerte connotación "servil" y al mismo desprestigio social del que es objeto el trabajo reproductivo. De esta manera, mientras el imaginario "servil" predomina en las actividades que realiza una empleada del hogar, afecta en menor medida al repartidor de pizzas que trabaja en una empresa que sirve comida a domicilio, aunque en ambos casos se trate de externalización de trabajo reproductivo. 
Por lo tanto, la feminización de estos servicios no obedece únicamente a la proliferación de empleos precarios y de baja calidad, sino al hecho de que son actividades que se desarrollan en el ámbito privado del hogar, con la consiguiente invisibilidad y desprotección ante eventuales abusos que ello conlleva; que presentan una fuerte connotación servil, al estar íntimamente vinculadas a la figura del criado/criada tradicional y, por último, que han sido socialmente construidas como una mera extensión del trabajo reproductivo, atribuido desde siempre a las mujeres y sin percibir remuneración ni reconocimiento social a cambio. Por todo ello, estas actividades, una vez traspasadas al mercado, no se desprenden del imaginario de la "servidumbre", del estigma de "tareas propias de mujeres", de la descualificación (tareas a las que cualquiera puede acceder sin especial especialización) y de la desvalorización social y económica. Constituyen, sin lugar a dudas, el último peldaño de la marginalidad en términos de cualificación, estatus y salario (Borderías, 1991).

La pregunta clave es saber quién va a realizar estas tareas de "servidor". Las principales candidatas van a ser preferentemente mujeres sin estudios, con necesidades económicas y, cada vez más, mujeres de otra etnia, las que, a falta de otra salida laboral, cubren estos empleos y suavizan la tensión entre oferta y demanda. Adoptando las conclusiones de Torns (1995; 1997; 1999b), los empleos en los servicios de proximidad no sólo refuerzan la segregación ocupacional de las mujeres en el mercado de trabajo a nivel horizontal, sino que, además, a nivel vertical, sitúan a las nuevas empleadas en las categorías profesionales más bajas, por lo que se refuerza una estructura ocupacional cada vez más dual. El aumento del nivel educativo y de las expectativas laborales de las mujeres autóctonas conlleva una insuficiente oferta de fuerza de trabajo femenina para prestar estos servicios, cuya demanda crece exponencialmente. La llegada de mujeres inmigrantes se erige como la solución factible para rellenar este vacío en el mercado de trabajo. Es así como se materializa la triple discriminación (a partir de la clase, el género y la etnia) de la mujer inmigrante, que llega a Cataluña atraída por la fuerte demanda en este sector, y a la que la sociedad receptora no brinda otras salidas laborales.

\section{LA ESTRUCTURA DE LA OFERTA DE SERVICIOS DE PROXIMIDAD EN CATALUNYA ${ }^{13}$}

La estructura de la oferta de servicios de proximidad, lejos de constituir un sector homogéneo, se configura a partir de distintas modalidades. Dichas modalidades se distinguen entre sí, principalmente, en función del tipo de servicios ofertados

\footnotetext{
${ }^{13}$ Este apartado se ha confeccionado a partir de los resultados obtenidos en el trabajo de campo realizado en la Tesis Doctoral, La internacionalización de la reproducción. La inserción laboral de
} 
R I S

REVISTA INTERNACIONAL DE SOCIOLOGIA

№36, Septiembre-Diciembre, 2003

SÒNIA PARELLA I RUBI0

y de su grado de profesionalización, así como del tipo de relación laboral que mantiene la persona que presta el servicio. Ambos elementos permiten diseñar una jerarquía dentro de los servicios de proximidad, que revela la existencia de un proceso de segmentación en los términos de Piore (1983a; 1983b), que se recoge en la figura 1.

En la base de dicha estructura jerarquizada se sitúa el servicio doméstico tradicional, en concreto el subsector "interno" (la trabajadora trabaja para un único usuario, que ejerce de empleador directo, en cuyo hogar reside). En el segundo nivel de la jerarquía se encuentran el resto de subsectores dentro del servicio doméstico, tanto las empleadas externas "fijas" como las asistentas "por horas". No sólo la relación laboral del servicio doméstico es de carácter especial (el Real Decreto de 1985 regula la relación laboral del Servicio del Hogar Familiar), sino que también existe un régimen especial en el sistema de la seguridad social para estos empleados, denominado régimen especial de las Empleados de Hogar (REEH), con una cobertura claramente discriminatoria, inferior a la garantizada por el Régimen General.

Figura 1.

Segmentación de los servicios de proximidad.

\begin{tabular}{|l|l|}
\hline \multicolumn{2}{|c|}{ Empresas no intermediarias con financiación pública (TIPO 3) } \\
\hline \multicolumn{2}{|c|}{$\begin{array}{c}\text { Empresas no intermediarias } \\
\text { sin financiación pública (TIPO 2) }\end{array}$} \\
\hline $\begin{array}{l}\text { Servicio doméstico tradicional externo } \\
\text { ("fijas" y "asistentas por horas") }\end{array}$ & A través de empresas intermediarias (TIPO 1) \\
\cline { 2 - 2 } & Por "cuenta propia" \\
\hline \multicolumn{2}{|c|}{ Servicio doméstico tradicional interno } \\
\hline
\end{tabular}

Fuente: Elaboración propia.

la mujer inmigrante en los servicios de proximidad, presentada por Sònia Parella en el Departament de Sociologia de la UAB en el año 2002. En lo que concierne al servicio doméstico tradicional, se parte de datos secundarios, tanto procedentes de fuentes estadísticas oficiales como de anteriores investigaciones que se han centrado en esta temática en el ámbito español. Para el caso de las empresas de servicios domiciliarios se han obtenido datos primarios cualitativos en el Área Metropolitana de Barcelona, desde una doble perspectiva: por un lado, la de las empresas, a través de la figura de los gerentes (entrevistas semiestructuradas); por el otro, la de las mujeres asalariadas, tanto inmigrantes no comunitarias como autóctonas, que se emplean en dichas empresas (grupos de discusión). 
Sin lugar a dudas, nos encontramos ante una normativa que ratifica una relación contractual débil, favorecedora del "servilismo", puesto que sólo fija unos mínimos que sitúan a las personas empleadas a merced del empleador, y que goza de un gran margen de discrecionalidad a la hora de definir las condiciones laborales y de rescindir la relación laboral. Además, puesto que el servicio doméstico se presta en el propio hogar, favorece la invisibilidad de quien lo realiza, de modo que se convierte en un marco idóneo para el incumplimiento de los mínimos que la normativa establece y para las situaciones de explotación. Si bien se otorga a este sector el estatuto jurídico de relación laboral, sus empleados son considerados "trabajadores de segunda", ya que están más desprotegidos y reciben muchas menos prestaciones que las que recoge el Estatuto de Trabajadores.

Alternativamente al servicio doméstico tradicional, otra modalidad, todavía incipiente aunque con un gran potencial de expansión, está constituida por las empresas de servicios domiciliarios. Las "empresas intermediarias" (TIPO 1), se caracterizan por no contratar directamente a su plantilla y ejercer una función de intermediarias entre la oferta y la demanda. Dichas empresas ofrecen una vinculación laboral externa, puesto que la persona que presta el servicio carece de contrato de trabajo ordinario y no cotiza en el Régimen General de la Seguridad Social, lo que genera puestos de trabajo con condiciones laborales similares a las del servicio doméstico $\mathrm{y}$, por consiguiente, con una fuerte incidencia de la economía informal. En contraposición, un segundo gran grupo, las "empresas no intermediarias", está integrado por entidades cuyo personal sí mantiene relación laboral con la empresa, lo que supone para la plantilla el goce de las prestaciones del Régimen General de la Seguridad Social. Estas empresas, a su vez, pueden ser subdivididas en dos segmentos: por un lado, aquellas empresas que sólo ofertan servicios privados, no financiados desde la Administración (TIPO 2); por el otro, las empresas que cuentan con un importante volumen de servicios financiados por la Administración (TIPO 3), lo que significa una mejora de las condiciones laborales de la plantilla y un incremento de su estabilidad laboral.

De la jerarquización de los servicios de proximidad se deriva un proceso de segmentación en función de la etnia dentro de los servicios vinculados a la reproducción social. Aunque las trabajadoras inmigrantes y determinados perfiles de trabajadoras autóctonas conviven en los servicios de proximidad (más arriba se ha indicado que las mujeres autóctonas todavía representan cerca de un $80 \%$ del total de la fuerza de trabajo en el servicio doméstico, aunque dicha proporción se va reduciendo), no se concentran en las mismas modalidades, tal como reproduce la Figura 2.

Las trabajadoras inmigrantes son confinadas en las modalidades menos deseadas y valorizadas. Así lo certifica el hecho que la mujer inmigrante se concentre preferentemente en la modalidad del servicio doméstico interno, una modalidad cuya demanda crece en los últimos años (a consecuencia, principalmente, del envejecimiento de la población) y que se enfrenta a la casi total ausencia de mujeres 
RIS

REVISTA INTERNACIONAL DE SOCIOLOCIA

Figura 2.

La etnización de los servicios de proximidad.

\begin{tabular}{|l|l|}
\hline $\begin{array}{l}\text { Empresas servicios domiciliarios no } \\
\text { intermediarias }\end{array}$ & $\begin{array}{l}\text { Predominio fuerza de trabajo autóctona } \\
\text { Excepcionalmente, determinados perfiles de } \\
\text { mujeres inmigrantes }\end{array}$ \\
\hline Servicio Doméstico Externo & $\begin{array}{l}\text { Concurre tanto fuerza de trabajo autóctona } \\
\text { como inmigrante }\end{array}$ \\
\hline Servicio Doméstico Interno & Concentración de mujeres inmigrantes \\
\hline
\end{tabular}

Fuente: Elaboración propia

autóctonas dispuestas a emplearse en ella. Las trabajadoras inmigrantes son reclutadas en el servicio doméstico interno tanto a través de contactos proporcionados por sus propias redes migratorias, como a través de empresas intermediarias en las que se inscriben una vez en la sociedad receptora. Ya no existe reemplazo generacional para las empleadas autóctonas "internas", que procedían de las zonas rurales y que abandonaban el servicio doméstico interno en cuanto se casaban. Esta situación permite demostrar la existencia de un proceso de sustitución entre empleadas autóctonas e inmigrantes, de manera que las últimas son reemplazadas por las primeras.

El "nivel de aceptación" de un empleo constituye un concepto clave para comprender las estrategias de los distintos colectivos a la hora de aceptar una determinada modalidad de empleo (Villa, 1990). En lo que concierne a las mujeres inmigrantes, tanto sus imperiosas necesidades económicas como el diferencial salarial con respecto a los países de origen favorece que acepten en la sociedad receptora salarios y condiciones laborales por debajo de las que están dispuestas a suscribir las trabajadoras autóctonas o las propias inmigrantes en sus países de origen. En el caso del servicio doméstico interno, por cuanto favorece la estabilidad laboral y el ahorro económico, se amolda a las necesidades y objetivos de las mujeres inmigrantes que emigran solas, dejando a sus familias en el país de origen, con el firme propósito de mandar la máxima cantidad de dinero en el mínimo tiempo posible y, posteriormente, retornar a su lugar de origen.

En el servicio doméstico externo y en la modalidad de asistentas por horas, en cambio, concurren tanto las mujeres autóctonas como las inmigrantes, lo que configura una relación de competencia entre ambos colectivos de trabajadoras; al menos a corto plazo, puesto que las empleadas domésticas autóctonas son 
habitualmente mujeres mayores de $40 \mathrm{años}^{14}$. Mientras la mujer inmigrante que abandona el servicio doméstico interno se concentra en mayor medida en la modalidad de empleada externa para un único empleador (a quien corresponde el pago de las cotizaciones a la Seguridad Social si la duración del servicio sobrepasa la mitad de la jornada habitual), la figura de la "asistenta por horas" es más recurrente entre las trabajadoras autóctonas. Para las mujeres inmigrantes, en el tránsito del servicio doméstico interno hacia el externo influyen la antigüedad en el asentamiento en la sociedad receptora, contar con un nivel educativo superior al requerido por la actividad que realizan (inconsistencia de estatus), el hecho de que la familia resida en la sociedad receptora, así como disponer de redes sociales que faciliten los contactos. En este sentido, las mujeres inmigrantes que carecen de la ayuda de las redes sociales (a raíz de un cambio de municipio de residencia, por ejemplo), compiten con desventaja a la hora de encontrar "casas por su cuenta", ya que su condición de extranjeras despierta reticencias entre los potenciales clientes de un mercado anónimo. Para estas mujeres, el pago de una cuota a una empresa intermediaria les supone un respaldo y les garantiza poder contar con servicios de forma rápida.

En el nivel más alto de la jerarquía, las "empresas no intermediarias", el trabajo de campo muestra que constituye un segmento integrado fundamentalmente por mujeres autóctonas, aunque no se dispone de datos estadísticos al respecto. Sus condiciones laborales más "atractivas" se traducen en una incipiente relación de competencia entre la fuerza de trabajo autóctona y la inmigrante, aunque, de momento, la presencia de trabajadoras inmigrantes es muy reducida. En estas empresas se emplea a mujeres autóctonas que proceden de otras modalidades de los servicios de proximidad (generalmente sumergidas), o bien de la inactividad, que cuentan con un bajo nivel educativo y que han obtenido, en muy poco tiempo, una cualificación profesional que las capacita para trabajar en los servicios domiciliarios (excepto cuando se trata de servicios de limpieza). Se trata de trabajadoras de edad avanzada, a las que el mercado de trabajo no ofrece más que estas oportunidades laborales, que viven su trabajo remunerado con una mezcla de vocación y resignación y, por lo general, tanto su salario como cotizar en la Seguridad Social es vital para sus economías familiares (a menudo son mujeres separadas, divorciadas o viudas, que encabezan familias monoparentales).

Junto a ellas, se detecta un pequeño grupo de mujeres inmigrantes - que irá, sin lugar a dudas, creciendo en un futuro próximo-- con un nivel educativo elevado, con un tiempo considerable de permanencia en la sociedad receptora y con voluntad de establecerse en ella de manera definitiva. Habitualmente se limitan a cubrir los servicios más periféricos e inestables, por lo que en raras ocasiones

\footnotetext{
${ }^{14}$ Las generaciones de mujeres más jóvenes van a tener expectativas laborales distintas.
} 


\section{R IS}

forman parte del núcleo estable de la plantilla. Se trata de mujeres inmigrantes, por lo general, más exigentes en su "nivel de aceptación" de una ocupación, no movidas únicamente por una motivación económica y con un acusado deseo de superación personal. En consecuencia, su presencia en la empresa es resultado de una estrategia de inversión en capital humano: han obtenido una titulación en la sociedad receptora (auxiliar de geriatría, trabajadora familiar, etc.) que les permite acreditar cualificación profesional y dar el salto del servicio doméstico tradicional hacia una empresa de servicios domiciliarios no intermediaria. Ello se traduce en un proceso de movilidad ocupacional ascendente dentro de los servicios de proximidad.

Hasta el momento se han destacado aquellos aspectos de las características personales del colectivo de mujeres inmigrantes (capital cultural, diferencias culturales en torno al concepto "occidental" de higiene, etc.) y de suš estrategias (nivel de aceptación, proyecto migratorio, tiempo de asentamiento en la sociedad receptora) que influyen en la progresiva etnización de los servicios de proximidad menos valorados. Asimismo, la etnización de los servicios de proximidad también se explica por las configuraciones ideológicas estereotipadas procedentes de la demanda de la fuerza de trabajo, en el sentido de preferir a la mujer inmigrante para determinadas tareas antes que a la mujer autóctona (selección preferente) y de rechazarla para desempeñar otras actividades (discriminación negativa).

En este sentido, de las entrevistas se desprende que las prácticas manifestadas por los gerentes de las empresas de servicios domiciliarios a la hora de reclutar personal coinciden perfectamente con las preferencias de sus clientes. Los usuarios que, o bien optan por el servicio doméstico tradicional, o bien contratan los servicios de las empresas intermediarias, prefieren a las candidatas inmigrantes (sobre todo para llevar a cabo tareas de cuidado de personas ancianas), a tenor de una serie de factores que se basan en la interrelación entre el género y la etnia: (1) creen que les va a suponer mayor ahorro económico (salarios más bajos y, en muchos casos, ahorro de las cotizaciones sociales); (2) presuponen que la condición de inmigrantes convierte a las trabajadoras en menos exigentes y menos reivindicativas, lo que incrementa la relación de poder que puede ejercer el usuario (protección a cambio de obediencia); (3) atribuyen a la mujer inmigrante una serie de criterios estereotipados de naturaleza personal (modo de ser), no profesional, que varían según colectivo. En las empresas intermediarias, por lo general, no se exige titulación o formación específica a la plantilla a la hora de reclutarla (salvo cuando se trata de servicios sanitarios), por cuanto, si lo hicieran, se enfrentarían a graves dificultades para encontrar fuerza de trabajo dispuesta a emplearse bajo las pésimas condiciones laborales que ofrecen.

Tales estrategias de reclutamiento permiten entender por qué las trabajadoras autóctonas se sienten "amenazadas" por la presencia de fuerza de trabajo inmigrante, al considerar que su menor "nivel de aceptación" de un empleo origina un 
dumping social que deteriora las condiciones laborales del conjunto del sector y obstaculiza su profesionalización. Es así como las empleadas autóctonas perciben que están perdiendo "posiciones" dentro de las preferencias de las personas empleadoras. Además, las trabajadoras autóctonas responsabilizan a las mujeres inmigrantes de que se haya reducido su "poder social de negociación" a la hora de fijar sus condiciones de empleo, de modo que sus exigencias y "conquistas" salariales han dejado de ser competitivas.

Sin embargo, dicha relación de competencia entre ambos colectivos, lejos de manifestarse de manera explícita, se expresa mediante recurrentes críticas hacia las mujeres inmigrantes (referentes tanto a sus capacidades profesionales como a sus características personales), a partir de estereotipos cuya finalidad es degradar la calidad de los servicios cuando son ellas las que los realizan. Efectivamente, la situación de competencia entre las trabajadoras inmigrantes y determinados segmentos de la fuerza de trabajo autóctona genera criterios de diferenciación, discriminación y exclusión que ponen el acento en los factores de etnia y de cultura (Solé, 1995). Un discurso análogo sostienen los gerentes de las empresas no intermediarias, plenamente conscientes de que muchas de las modalidades más "rentables" dentro de los servicios de proximidad se sostienen gracias al reclutamiento de trabajadoras inmigrantes.

En las empresas de servicios no intermediarias, en cambio, a tenor de sus características, los mecanismos de asignación de los puestos de trabajo y de retribución siguen pautas más formalizadas, por lo que el componente étnico tiene menor peso en las realidades laborales. Las estrategias de selección de personal se basan principalmente en la cualificación profesional de las trabajadoras (experiencia y titulación). De ese modo, ateniéndonos a lo apuntado por los gerentes de las empresas que han sido entrevistados, las trabajadoras autóctonas y las inmigrantes compiten en igualdad de condiciones en las empresas no intermediarias, siempre que las candidatas inmigrantes reúnan una serie de requisitos: (1) un estatuto jurídico estable (mejor si tienen la nacionalidad española); (2) el asentamiento más o menos definitivo en la sociedad receptora (lo que garantiza que posean las mismas pautas y referentes culturales que las trabajadoras autóctonas); (3) una titulación específica (auxiliar de geriatría, trabajadora familiar, auxiliar del hogar, etc.) que acredite su cualificación para llevar a cabo servicios domiciliarios.

Sin embargo, debe tenerse en cuenta que el segmento de clientes que opta por las empresas no intermediarias está dispuesto a pagar un precio más elevado por los servicios a cambio de profesionalidad. Por ello, no es de extrañar que las preferencias de estos usuarios se basen a menudo en la sistemática discriminación de las trabajadoras de origen inmigrante, con independencia de cuáles sean sus características personales, al asociar su presencia con las modalidades menos cualificadas de los servicios de proximidad. Esta situación incentiva la formulación de políticas de contratación discriminatorias en base a la etnia por parte de algunas empresas, lo que desplaza a las mujeres inmigrantes hacia otras 
modalidades de los servicios de proximidad (empresas intermediarias y servicio doméstico tradicional) y agudiza aún más el proceso de etnización. Tales políticas de exclusión de la fuerza de trabajo inmigrante son poco viables a corto plazo, ya que, paralelamente al crecimiento exponencial de la demanda de estos servicios, se constata la escasez estructural de mujeres autóctonas dispuestas a llevarlos a cabo $\mathrm{y}$, menos aún, acreditadas con una titulación específica. Por lo tanto, es obvio que la fuerza de trabajo inmigrante constituye, sin lugar a dudas, el recurso humano por excelencia del que se van a nutrir también las modalidades más cualificadas de los servicios de proximidad en el futuro.

\section{CONCLUSIONES}

Los servicios de proximidad constituyen una de las principales oportunidades de inserción laboral para la mayoría de mujeres inmigrantes extracomunitarias en Cataluña. A pesar de su inmenso potencial de crecimiento y de la gran heterogeneidad de situaciones laborales que engloban, adolecen en su conjunto de falta de regulación y se están expandiendo mediante la creación de puestos de trabajo caracterizados por los bajos ingresos, las malas condiciones de trabajo, el escaso grado de organización colectiva, la precariedad laboral, los altos índices de economía sumergida y las limitadas posibilidades de promoción laboral. Tales características propias del mercado de trabajo secundario, junto al imaginario social que concibe los servicios de proximidad como "tareas" poco valoradas y propias de mujeres, les convierte en un sector fuertemente feminizado, ocupado preferentemente por mujeres autóctonas con un bajo nivel educativo y, cada vez más, por mujeres inmigrantes.

El insuficiente desarrollo de las prestaciones económicas y los servicios para las familias desde el Estado del bienestar, ha facilitado que las dificultades de conciliación entre la vida familiar y laboral se resuelvan a través de formas mercantiles, que se concretan en el reclutamiento de "otras" mujeres (las trabajadoras inmigrantes), en el contexto de un mercado de trabajo que opera a escala internacional, para llevar a cabo determinadas labores reproductivas que hasta ahora habían realizado las mujeres autóctonas en el seno del hogar y de forma gratuita. La falta de implicación del sector público en términos de financiación de estos servicios privados, unido a la insolvencia de la demanda, ha propiciado que se opte por las modalidades más baratas y menos reguladas de la prestación de estos servicios: el servicio doméstico tradicional, tanto en su modalidad formal como informal, así como por el recurso a trabajadores de origen inmigrante.

Los resultados del trabajo de campo realizado en Cataluña con gerentes y trabajadoras en empresas de servicios domiciliarios, corroboran la existencia de una jerarquía dentro de los servicios de proximidad, en la que conviven las 
trabajadoras autóctonas e inmigrantes. En dicha estructura jerarquizada, ambos colectivos de mujeres (autóctonas e inmigrantes) se enfrentan a estrategias de inserción laboral distintas y a procesos de reclutamiento y de exclusión también específicos, basados en la conjunción entre la etnicidad de las trabajadoras (o condición social de extranjeras) y las características inherentes a las distintas actividades. Esta situación da lugar a relaciones de competencia y sustitución entre ambas fuerzas de trabajo (Solé, 1995).

Desentrañar cómo se manifiesta el proceso de etnización de los servicios de proximidad - es decir, cuáles son los factores que determinan las posiciones que ocupan las mujeres autóctonas e inmigrantes-, ha sido uno de los principales objetivos del artículo. La etnización de los servicios vinculados a la reproducción social no sólo depende de las características personales del colectivo de mujeres inmigrantes (capital cultural, diferencias culturales en torno al concepto "occidental" de higiene, etc.) y de sus estrategias (nivel de aceptación, proyecto migratorio, tiempo de asentamiento en la sociedad receptora), sino que también es resultado de una serie de procesos de carácter estructural que relegan a la mujer inmigrante a los servicios vinculados a la reproducción social, sin olvidar las configuraciones ideológicas estereotipadas procedentes de la demanda de la fuerza de trabajo.

\section{REFERENCIAS BIBLIOGRÁFICAS}

ALBERDI, I. et al. (2000), Les dones joves a Espanya, Barcelona, Fundació "La Caixa".

ANDERSON, B. (2000), Doing the Dirty Work? The Global Politics of Domestic Labour, Londres, Zed Books.

BONNET, M. y Y. BERNARD (ed.). (1998), Services de proximité et vie quotidienne. De nouvelles sociabilité urbaines, París, Presses Universitaires de France.

BORDERÍAS, C. (1991), "Las mujeres, autoras de sus trayectorias personales y familiares a través del servicio doméstico", Historia y Fuente Oral, n 6, pp.105-121.

BRULLET, C. (2000), "El debat sobre la conciliació ocupació-família dins el marc de la Unió Europea", Revista Catalana de Sociologia, n 12, pp.155-186.

(2002), "Les polítiques de conciliació de la vida professional i la vida familiar, el cas dels serveis de suport a les famílies", en L. Flaquer (dir.), Informe sobre la situació de la familia a Catalunya. Un intent de diagnòstic, Barcelona, Generalitat de Catalunya.

CACHÓN, L. (1997), "La formación y los nuevos yacimientos de empleo en España", Revista Española de Investigaciones Sociológicas, $\mathrm{n}^{\circ}$ 77-78, pp. 117-136.

CATARINO, C.y L. OSO (2000), "La inmigración femenina en Madrid y Lisboa, hacia una etnización del servicio doméstico y de las empresas de limpieza", PAPERS. Revista de Sociología, nº 60, pp.187-207. 
COLECTIVO IOÉ (2001a), "Flujos migratorios internacionales. Marco de comprensión y características actuales", Migraciones, $\mathrm{n}^{\circ} 9, \mathrm{pp} .7-44$.

(2001b), iNo quieren ser menos! Exploración sobre la discriminación laboral de los inmigrantes en España, Madrid, UGT.

(2001c), Mujer, inmigración y trabajo, Madrid, Ministerio de Trabajo y Asuntos Sociales, Colección Observatorio Permanente de la Inmigración.

ESPING-ANDERSEN, G. (1993), “Empleo postindustrial y estratificación”, ponencia presentada en el $I$ Simposio sobre igualdad y distribución de la renta y la riqueza, Madrid, 24-28 de mayo de 1993.

(1996), “IIgualdad o empleo? La interacción de salarios, Estados de Bienestar y cambio familiar”, en AA.VV, Dilemas del Estado de Bienestar, Madrid, Fundación Argentaria.

(1999), Social Foundations of Postindustrial Economies, Oxford, Oxford University Press.

FLAQUER, L. (2000), Les politiques familiars en una perspectiva comparada, Barcelona, Fundació "La Caixa".

FLAQUER, L. y C. BRULLET (1999), Politiques familiars a Catalunya: una primera aproximació, Barcelona, Fundació Jaume Bofill.

FRAISE, G. (2000), "Servidumbre, empleos de servicio y democracia",en M. Maruani et al. (ed.), Las nuevas fronteras de la desigualdad, Barcelona, Icaria.

FUNDACIÓ CIREM (1999), Los nuevos yacimientos de empleo.Los retos de la creación de empleo desde el territorio, Barcelona, Icaria.

GENERALITAT DE CATALUNYA (2001), Llibre blanc dels nous jaciments d'ocupació, Barcelona, Generalitat de Catalunya.

GREGSON, N. y M. LOWE (1994), Servicing the Middle Classes, Londres, Routledge.

IMU (2002), Mujeres en cifras 1996-2000, Madrid, Ministerio de Trabajo y Asuntos Sociales.

MOMSEN, J.H. (1999), Gender, Migration and Domestic Service, Londres, Routledge.

PARELLA, S. (2003), Mujer, inmigrante y trabajadora. La triple discriminación, Barcelona, Anthropos.

PÉREZ DEL RÍO, T. (1998), “Los ‘servicios de proximidad’, ¿un nuevo yacimiento de empleo”?. Documento inédito

PIORE, M.J. (1983a), "Notas para una teoría de la estratificación del mercado de trabajo", en L. Toharia (ed.), El mercado de trabajo: Teorias y Aplicaciones, Madrid, Alianza Universidad.

(1983b), "El dualismo como respuesta al cambio y la incertidumbre", en L. Toharia (ed.), El mercado de trabajo: Teorias y Aplicaciones, Madrid, Alianza Universidad. 
QUESADA, R. (1991), El contrato de servicio doméstico, Madrid, La Ley.

SASSEN, S. (1984), "Notes on the Incorporation of Third World Women into Wage-Labor Through Immigration and Off-Shore Production", International Migration Review, vol. 18, n⿳⺈, pp. 1144-1165.

(1993), La movilidad del trabajo y del capital, Madrid, Ministerio de Trabajo y Seguridad Social.

(1994), "Why Migration? Tesis contra los modelos de explicación al uso", en AA.VV, Extranjeros en el paraiso, Barcelona, Virus.

(1998), Globalization and Its Discontents, NuevaYork, The New Press.

SOLÉ, C. (1995), Discriminación racial en el mercado de trabajo, Madrid, CES.

TEZANOS, J.F. (2001), El trabajo perdido. ¿Hacia una civilización postlaboral?, Madrid, Biblioteca Nueva.

TORNS, T. (1995), "Los nuevos empleos, cualificación y valoración”, comunicación presentada en el Séminaire IRIS: Une vision plus large, Bruselas, junio 1995.

(coord). (1996) "La Formation pour les emplois de proximité. Note de reflexion au vue du rapport de genre", Bellaterra, QUIT-Universitat Autònoma de Barcelona, Informe de investigación.

(1997), “Los servicios de proximidad, ¿un yacimiento de empleo?”, Revista de Treball Social, $\mathrm{n}^{\circ} 147$, pp. $40-54$.

(1999a), "Los trabajadores asalariados, desigualdades de género", en F. Miguélez y C. Prieto (ed.), Las relaciones de empleo en España, Madrid, Siglo XXI.

(1999b), "El futuro del empleo femenino y los yacimientos de empleo", Comunicación presentada en la Conferencia Internacional sobre El empleo y las sociedades avanzadas, Sevilla, Instituto de Desarrollo Regional, abril 1999.

VILLA, P. (1990), La estructuración de los mercados de trabajo, Madrid, MTSS. 